\title{
Pengaruh kepuasan dan kepercayaan terhadap loyalitas pelanggan dengan komitmen sebagai variable intervening
}

\author{
${ }^{1 *}$ Tika Nur Aini \\ ${ }^{I}$ Fakultas Ekonomi, Universitas Sarjanawiyata Tamansiswa, Jalan Kusumanegara Yogyakarta 55165 \\ *e-mail korespondensi: tikana722@gmail.com
}

\begin{tabular}{l|l}
\hline \hline \multicolumn{1}{c}{ Keywords } & \multicolumn{1}{c}{ Abstract } \\
\hline \hline $\begin{array}{l}\text { satisfaction, trust, } \\
\text { customer loyalty, } \\
\text { commitment }\end{array}$ & $\begin{array}{l}\text { The purpose of this study was to examine the significant effect of satisfaction and } \\
\text { trust on customer loyalty with commitment as an intervening variable (case study in } \\
\text { Yogyakarta customers). The variables of this study are satisfaction, trust, customer } \\
\text { loyalty and commitment. The population in this study were JNE Yogyakarta } \\
\text { customers whose numbers could not be known. So that the number of samples of this } \\
\text { study is 100 obtained from the formula, with purposive sampling method, the method } \\
\text { of data collection using questionnaires. While the data analysis technique uses } \\
\text { multiple linear regression analysis supported by t test, F test, R2 test and classic } \\
\text { assumption test consisting of normality test, heterocedasticity test, multicollinearity } \\
\text { test and sobel test. }\end{array}$ \\
\hline \hline \multirow{2}{*}{$\begin{array}{l}\text { Kata Kunci } \\
\text { kepuasan, } \\
\text { loyalitas pelanggan, } \\
\text { komitmen }\end{array}$} & $\begin{array}{l}\text { Tujuan penelitian ini adalah untuk menguji pengaruh signifikan kepuasan dan } \\
\text { kepercayaan terhadap loyalitas pelanggan dengan komitmen sebagai variabel } \\
\text { intervening (studi kasus pelanggan di Yogyakarta). Variabel penelitian ini adalah } \\
\text { kepuasan, kepercayaan, loyalitas pelanggan dan komitmen. Populasi dalam } \\
\text { penelitian ini adalah pelanggan JNE Yogyakarta yang jumlahnya tidak dapat } \\
\text { diketahui. Sehingga jumlah sampel penelitian ini sebanyak 100 yang diperoleh dari } \\
\text { rumus, dengan metode purposive sampling, metode pengumpulan datanya } \\
\text { menggunakan kuesioner. Sedangkan teknik analisis datanya menggunakan analisis } \\
\text { regresi linier berganda yang didukung dengan uji t, uji F, uji R2 dan uji asumsi klasik } \\
\text { yang terdiri dari uji normalitas, uji heteroskedastisitas, uji multikolinieritas dan uji } \\
\text { sobel. }\end{array}$ \\
\hline \hline
\end{tabular}

\section{PENDAHULUAN}

Perkembangan bisnis saat ini sangat pesat baik yang berskala kecil, menengah maupun yang berskala besar dan banyak para pelaku bisnis saat ini yang menjalankan bisnis mereka dengan menggunakan media internet atau melakukan penjualan secara online. Penjualan yang dilakukan secara online akan membuat semakin luas jaringan pemasarannya dan mendatangkan pelanggan dari berbagai daerah. Hal tersebut diikuti dengan pesatnya perkembangan perusahaan penyedia jasa pengiriman barang. 
JNE adalah salah satu perusahaan jasa pengiriman barang yang cukup dikenal oleh masyarkat dari beberapa perusahaan jasa pengiriman barang yang lain. Selain JNE di Indonesia sendiri sudah banyak sekali yang mendirikan perusahaan jasa pengiriman barang seperti seperti J\&T Express, TIKI, Pos Indonesia, dan DHL dan beberapa tahun belakangan ini perusahan jasa pengiriman barang saling bersaing untuk mempertahankan pelanggannya.

Menurut Gofur (2019) kepuasan pelanggan adalah hasil akumulasi dari konsumen atau pelanggan dalam menggunakan produk atau jasa. Selain kepuasan pelanggan menjadi faktor penting yang mendukung terjadinya loyalitas pelanggan, kepercayaan pelanggan juga perlu diperhatikan oleh JNE karena, saat pelanggan merasa percaya dengan suatu layanan jasa maka kemungkinan besar meraka akan menggunakan kembali layanan jasa yang sama.

Kepercayaan menurut Rofiq \& Mula (2010) adalah kesediaan satu pihak untuk menerima resiko dari tindakan pihak lain berdasarkan harapan bahwa pihak lain akan melakukan tindakan penting untuk yang mempercayainya, dan mengendalikan tindakan pihak yang dipercaya.

Pelanggan yang merasa puas dan percaya akan berkomitmen untuk terus menggunakan produk atau jasa yang telah dirasakan secara berulang kali. Komitmen sendiri adalah suatu kondisi psikologis yang menggambarkan hubungan antara pelanggan dengan perusahaan, dan berdampak terhadap keputusannya untuk terus bertahan atau tetap menjadi pelanggan yang setia (Affandi \& Sulistyawati, 2015).

\section{TEORI DAN HIPOTESIS}

\section{Loyalitas Pelanggan}

Menurut Kotler dan Keller (2016) loyalitas pelanggan didefinisikan sebagai tingkat perasaan seseorang setelah Membandingkan kinerja (atau hasil) yang ia rasakan dibandingkan dengan harapannya dan pada akhirnya akan melakukan pembelian ulang. Menurut Dharmmesta (2014), loyalitas pelanggan adalah kondisi dimana konsumen mempunyai sikap positif terhadap sebuah merek, mempunyai komitmen pada merek tersebut, dan bermaksud meneruskan pembeliannya dimasa mendatang.

Indikator loyalitas pelanggan menurut Kotler dan Keller, (2016):

a) Minat pembelian ulang

b) Kesediaan untuk merekomendasi

\section{Kepuasan Pelanggan}

Menurut Gofur (2019) dan Idris et al. (2019) kepuasan pelanggan adalah hasil akumulasi dari konsumen atau pelanggan dalam menggunakan produk atau jasa. Menurut Lupiyoadi \& Hamdani (2008), kepuasan pelanggan adalah tingkat perasaan seseorang setelah membandingkan hasil yang ia rasakan dibandingkan dengan harapannya.

Indikator kepuasan pelanggan menurut Dharmesta \& Irawan (2012):
a) Perasaan puas
b) Selalu membeli produk
c) Terpenuhinya harapan pelanggan setelah membeli produk 
Menurut Tjiptono (2006) adanya suatu kepuasan pelanggan yang dirasakan akan memberikan beberapa manfaat bagi perusahaan, antara lain:

a) Hubungan antara perusahaan dan para pelanggan menjadi harmonis.

b) Memberikan dasar yang baik bagi pembelian ulang.

c) Dapat mendorong terjadinya loyalitas pelanggan.

d) Membentuk rekomendasi dari mulut ke mulut yang

e) menguntungkan bagi perusahaan.

f) Reputasi perusahaan menjadi baik di mata pelanggan.

g) Laba yang diperoleh perusahaan menjadi meningkat.

\section{Kepercayaan Pelanggan}

Menurut Rofiq \& Mula (2010) kepercayaan pelanggan adalah kesediaan satu pihak untuk menerima resiko dari tindakan pihak lain berdasarkan harapan bahwa pihak lain akan melakukan tindakan penting untuk yang mempercayainya, dan mengendalikan tindakan pihak yang dipercaya.

Muzammil et al. (2018) mendefinisikan kepercayaan sebagai kesediaan seseorang untuk menggantungkan dirinya kepada pihak lain yang terlibat dalam pertukaran karena ia mempunyai keyakinan kepada pihak lain tersebut.

Indikator Kepercayaan Pelanggan menurut Rofiq \& Mula (2010):

a) Kesungguhan/Ketulusan (Benevolence)

b) Kemampuan (Ability)

c) Integritas (Integrity)

\section{Komitmen}

Menurut Affandi \& Sulistyawati (2015) komitmen adalah suatu kondisi psikologis yang menggambarkan hubungan antara pelanggan dengan perusahaan, dan berdampak terhadap keputusannya untuk terus bertahan atau tetap menjadi pelanggan yang setia. Dharmmesta (2014) mendefinisikan bahwa komitmen merupakan hasrat atau keinginan kuat untuk mempertahankan dan melanjutkan relasi yang dipandang penting dan bernilai jangka panjang.

Indikator komitmen pelanggan menurut Affandi \& Sulistyawati (2011):

a) Memiliki ikatan dengan produk yang digunakan secara emosional.

b) Menjadi bagian dari layanan.

c) Sulit pindah ke produsen lain meski menginginkan.

d) Pertimbangan utama tetap menggunakan layanan produsen karena alasan ekonomi, psikologis, dan teknologi

\section{METODE PENELITIAN}

Penelitian ini dilakukan di Yogyakarta dan populasi dalam penelitian ini adalah pelanggan JNE Yogyakarta. Pengambilan sampel dalam penelitian ini diperoleh menggunakan rumus Rao Purba (Handal, 2010) yaitu: 


$$
\begin{aligned}
& \mathrm{N}=\frac{z 2}{4(m o e)^{2}} \\
& \mathrm{~N}=\frac{(1.96)^{2}}{4(0.1)^{2}} \\
& \mathrm{~N}=96,6 \text { dibulatkan } 97
\end{aligned}
$$

Keterangan:

N : Jumlah Sampel

z : Tingkat distribusi normal pada 5\% (1.96)

moe : Margin of error, yaitu tingkat kesalahan maksimum pengambilan sampel yang masih dapat ditoleransi $10 \%$

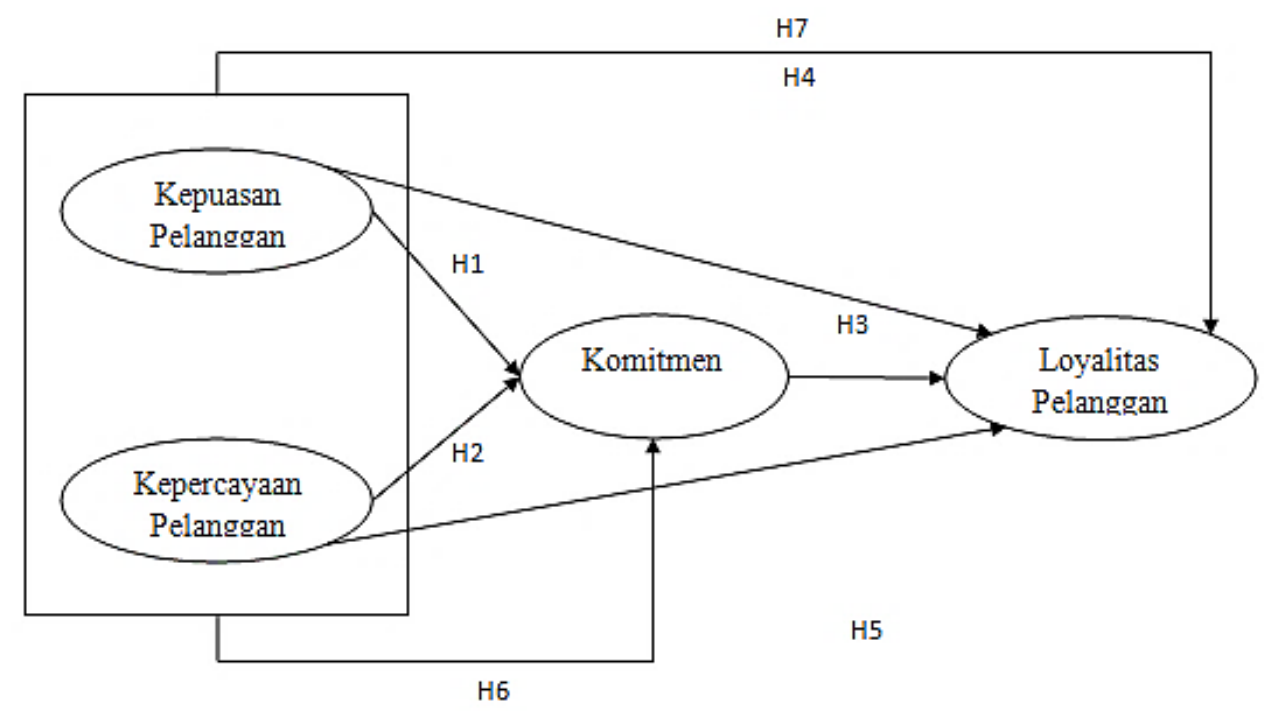

Gambar 1. Kerangka Pikir Penelitian

Peneliti menggunakan analisis data deskriptif dan kuanlitatif, uji validitas dan reabilitas, uji asumsi klasik yang diantaraya adalah Uji Normalitas, uji multikolinieritas dan uji heteroskesdisitas, selanjutnya uji analisis regresi linier berganda, pengujian hipotesis yaitu uji t, uji koefisien determinasi $\mathrm{R}^{2}$ dan uji sobel.

\section{HASIL DAN PEMBAHASAN}

Diketahui bahwa responden dengan karakteristik berdasarkan jenis kelaminn lebih didominasi oleh laki-laki sebanyak 55 orang (55\%). Kemudian rata-rata usia pengguna JNE adalah 16-25 tahun sebanyak 83 orang (83\%), pendidikan terakhir SMA terbanyak yaitu sebanyak 80 orang atau sebesar $80 \%$. sebanyak 66 orang atau sekitar $60 \%$ terdiri dari pelajar/ mahasiswa dengan pendapatan perbulannya $>2.000 .000$ sebanyak 45 orang atau $45 \%$.

Pengukuran uji validitas dapat dilakukan dengan cara membandingkan nilai $\mathrm{r}$ hitung dengan $\mathrm{r}$ tabel untuk degree of freedom $(\mathrm{df})=\mathrm{n}-2$, dimana adalah jumlah sampel responden. Kriteria instrumen dikatakan valid apabila nilai korelasi (Pearson Correlation) adalah positif dan nilai probabilitas korelasi \{ sig. < derajat signifikan $0,05(\alpha=5 \%)$. Berdasarkan tabel hasil uji validitas instrument menunjukkan bahwa nilai $r$ hitung $>\mathrm{r}$ tabel yang artinya semua butir pernyataan sebanyak 34 butir dinyatakan valid/sahih. 
Entrepreneurship Bisnis Manajemen Akuntansi (E-BISMA), 1(2), 88-98

Tika Nur Aini

Tabel 1

Uji Validitas Instrumen

\begin{tabular}{ccccc}
\hline Variabel & Butir & $\mathrm{R}_{\text {Hitung }}$ & $\mathrm{R}_{\text {Tabel }}$ & Hasil \\
\hline \multirow{5}{*}{ Kepuasan pelanggan $\left(\mathrm{X}_{1}\right)$} & Butir 1 & 0,493 & 0,197 & Valid \\
\hline & Butir 2 & 0,677 & 0,197 & Valid \\
\hline & Butir 3 & 0,727 & 0,197 & Valid \\
\cline { 2 - 5 } & Butir 4 & 0,774 & 0,197 & Valid \\
\hline & Butir 5 & 0,709 & 0,197 & Valid \\
\hline Butir 6 & 0,778 & 0,197 & Valid \\
\hline Butir 7 & 0,776 & 0,197 & Valid \\
\hline Butir 8 & 0,759 & 0,197 & Valid \\
\hline Butir 1 & 0,692 & 0,197 & Valid \\
\hline Butir 2 & 0,711 & 0,197 & Valid \\
\hline Butir 3 & 0,668 & 0,197 & Valid \\
\hline Butir 4 & 0,739 & 0,197 & Valid \\
\hline Butir 5 & 0,619 & 0,197 & Valid \\
\hline Butir 6 & 0,658 & 0,197 & Valid \\
\hline Butir 7 & 0,815 & 0,197 & Valid \\
\hline Butir 8 & 0,768 & 0,197 & Valid \\
\hline Butir 9 & 0,783 & 0,197 & Valid \\
\hline Butir 1 & 0,606 & 0,197 & Valid \\
\hline Butir 2 & 0,734 & 0,197 & Valid \\
\hline Butir 3 & 0,738 & 0,197 & Valid \\
\hline Butir 4 & 0,677 & 0,197 & Valid \\
\hline Butir 5 & 0,638 & 0,197 & Valid \\
\hline Butir 6 & 0,690 & 0,197 & Valid \\
\hline Butir 7 & 0,462 & 0,197 & Valid \\
\hline Butir 8 & 0,707 & 0,197 & Valid \\
\hline Butir 9 & 0,628 & 0,197 & Valid \\
\hline Butir 10 & 0,664 & 0,197 & Valid \\
\hline Butir 11 & 0,554 & 0,197 & Valid \\
\hline Butir 1 & 0,500 & 0,197 & Valid \\
\hline Butir 2 & 0,577 & 0,197 & Valid \\
\hline Butir 3 & 0,506 & 0,197 & Valid \\
\hline Butir 4 & 0,767 & 0,197 & Valid \\
\hline Butir 5 & 0,788 & 0,197 & Valid \\
\hline Butir 6 & 0,795 & 0,197 & Valid \\
\hline & & & & \\
\hline
\end{tabular}

Pengukuran uji reliabilitas pada penelitian ini menggunakan teknik Cronbach Alpha. Suatu instrument dikatakan reliabel jika memberikan nilai $>0,70$. Hasil uji reliabilitas dalam penelitian ini diolah menggunakan program SPSS for Windows 17. Berdasarkan data dapat diketahui bahwa variabel kualitas produk, harga, promosi dan brand imagekeempatnya memiliki nilai koefisien reliabilitas yang lebih tinggi dari pada Cronbanch Alpha yang 
disyaratkan yaitu sebesar 0,70 . Oleh karena itu, dapat dikatakan bahwa hasil instrumen ini memiliki tingkat reliabilitas yang tinggi, atau dapat dikatakan hasil instrumen ini dapat dipercaya.

Tabel 2

Uji Validitas Instrumen

\begin{tabular}{ccccc}
\hline No & Variabel & $\begin{array}{c}\text { Cronbach's } \\
\text { Alpha }\end{array}$ & $\begin{array}{c}\text { Cronbach's Alpha } \\
\text { yang disyaratkan }\end{array}$ & Hasil \\
\hline 1 & Kepuasan Pelanggan & 0.858 & 0.70 & Reliabel \\
\hline 2 & Kepercayaan Pelanggan & 0.879 & 0.70 & Reliabel \\
\hline 3 & Komitmen Pelanggan & 0.857 & 0.70 & Reliabel \\
\hline 4 & Loyalitas Pelanggan & 0.702 & 0.70 & Reliabel \\
\hline
\end{tabular}

Pengujian normalitas dalam penelitian ini digunakan dengan melihat normal probality plot yang membandingkan distribusi komulatif dari data sesungguhnya dengan distribusi kumulatif dari data normal. Berdasarkan gambar grafik normal probality plot dapat diketahui bahwa titik-titik mendekati garis diagonal yang berarti bahwa model regresi berdistribusi normal. Begitu juga dengan Dari hasil uji normalitas kolmogrov smirnov dengan dependen komitmen diketahui nilai signifikasi 0,607> $\alpha=0,05$ dan dependen loyalitas pelanggan $0,915>\alpha=0,05$. Maka dapat disimpulkan bahwa nilai residual terdistribusi normal.

Untuk mendeteksi adanya multikolinieritas dapat dilakukan dengan mencari besarnya Variance Inflation Factor (VIF) dan nilai tolerancenya. Jika VIF kurang dari 10 dan nilai tolerance lebih dari 0,10 maka regresi bebas dari multikolinieritas. Hasil uji multikolinearitas menunjukkan bahwa bahwa semua variabel mempunyai nilai toleransi di atas 0,10 dan nilai VIF di bawah 10, sehingga dapat disumpulkan bahwa model regresi pada penelitian ini tidak terjadi multikolinieritas.

Tabel 3

Koefisien Determinasi Komitmen Pelanggan

\begin{tabular}{ccccc}
\hline Model & $\mathrm{R}$ & $\mathrm{R}$ Square & $\begin{array}{c}\text { Adjusted R } \\
\text { Square }\end{array}$ & $\begin{array}{c}\text { Std. Error of the } \\
\text { Estimate }\end{array}$ \\
\hline 1 & $.760^{\mathrm{a}}$ & .578 & .569 & 2.88045 \\
\hline $\begin{array}{l}\text { a. Predictors: (Constant), Kepercayaan Pelanggan, Kepuasan Pelanggan } \\
\text { b. Dependent Variable: Komitmen Pelanggan }\end{array}$
\end{tabular}

Pengujian terhadap heteroskedastisitas dapat dilakukan melalui pengamatan terhadap pola scatter plot yang dihasilkan melalui SPSS. Apabila pola scatter plot membentuk pola tertentu, maka model regresi memiliki gejala heteroskedastisitas, munculnya gejala heteroskedastisitas menunjukkan bahwa penaksir dalam model regresi tidak efisien dalam sampel besar maupun kecil. Jika tidak ada pola yang jelas dan titik-titik menyebar di atas dan di bawah angka nol pada sumbu Y, maka dapat disimpulkan bebas heteroskedastisitas. Dari pengujian scatter plot dapat diketahui bahwa pola titik-titik menyebar di antara 0 
diagonal dan 0 vertikal maka dapat disimpulkan model regresi tidak terjadi heteroskedastisitas, uji ini diyakinkan dengan uji spearman's rho yang menunjukan nilai signifikasi dari semua variabel diatas 0,05 yang berarti semua data tidak terjadi gejala heterosdedastisitas.

Hasil perhitungan menunjukkan koefisien determinasi $\left(\mathrm{R}^{2}\right)$ antara kepuasan dan kepercayaan pelanggan sebesar $57,8 \%$ dan sisanya sebesar $42,2 \%$ dari komitmen pelanggan disebabkan oleh variabel lain diluar kepuasan dan kepercayaan pelanggan. Koefisien determinasi $\left(\mathrm{R}^{2}\right)$ kepuasan, kepercayaan dan komitmen pelanggan mempunyai pengaruh sebesar 38,5\% terhadap loyalitas pelanggan JNE Yogyakarta, sedangkan sisanya sebesar $61,5 \%$ dari loyalitas pelanggan disebabkan oleh variabel lain di luar ketiga variabel tersebut.

Tabel 4

Koefisien Determinasi Loyalitas Pelanggan

\begin{tabular}{ccccc}
\hline Model & $\mathrm{R}$ & R Square & $\begin{array}{c}\text { Adjusted R } \\
\text { Square }\end{array}$ & $\begin{array}{c}\text { Std. Error of the } \\
\text { Estimate }\end{array}$ \\
\hline 1 & $.620^{\mathrm{a}}$ & .385 & .365 & 1.47655 \\
\hline
\end{tabular}

a. Predictors: (Constant), Kepercayaan Pelanggan, Kepuasan Pelanggan

b. Dependent Variable: Loyalitas Pelanggan

\section{Pengujian Hipotesis}

\section{Uji t (parsial)}

Kepuasan terhadap komitmen memiliki tingkat signifikansi sebesar 0,000. Dari hasil uji t pada variabel iklan menyatakan bahwa signifikansi uji t lebih kecil dari 0,05 dan koefisien regresi mempunyai nilai positif sebesar 0,643 . Sedangkan nilai t hitung yang diperoleh yaitu 7,195 lebih besar dari nilai t tabel yaitu 1,984; maka hipotesis yang menyatakan bahwa "terdapat pengaruh positif kepuasan terhadap komitmen pelanggan JNE Yogyakarta diterima.

Kepercayaan terhadap komitmen memiliki tingkat signifikansi sebesar 0,000. Dari hasil uji t pada variabel iklan menyatakan bahwa signifikansi uji t lebih kecil dari 0,05 dan koefisien regresi mempunyai nilai positif sebesar 0,373 . Sedangkan nilai t hitung yang diperoleh yaitu 4,718 lebih besar dari nilai t tabel yaitu 1,984; maka hipotesis yang menyatakan bahwa "terdapat pengaruh positif kepercayaan terhadap komitmen pelanggan JNE Yogyakarta diterima.

Komitmen terhadap loyalitas pelanggan memiliki tingkat signifikansi sebesar 0,037. Dari hasil uji t pada variabel komitmen menyatakan bahwa signifikansi uji t lebih kecil dari 0,05 dan koefisien regresi mempunyai nilai positif sebesar 0,110 . Sedangkan nilai t hitung yang diperoleh yaitu 2,112 lebih besar dari nilai t tabel yaitu 1,984; maka hipotesis yang menyatakan bahwa "terdapat pengaruh positif komitmen terhadap loyalitas pelanggan JNE Yogyakarta diterima.

Kepercayaan terhadap loyalitas pelanggan memiliki tingkat signifikansi sebesar 0,031. Dari hasil uji t pada variabel komitmen menyatakan bahwa signifikansi uji t lebih kecil dari 0,05 dan koefisien regresi mempunyai nilai positif sebesar 0,098. Sedangkan nilai thitung 
yang diperoleh yaitu 2,188 lebih besar dari nilai t tabel yaitu 1,984; maka hipotesis yang menyatakan bahwa "terdapat pengaruh positif kepercayaan terhadap loyalitas pelanggan JNE Yogyakarta diterima.

\section{Uji F (simultan)}

Dari hasil pengujian diperoleh nilai $\mathrm{F}$ hitung sebesar 66,298 dengan nilai probabilitas sebesar 0,000. Berdasarkan dengan ketentuan uji $\mathrm{F}$ dimana nilai probabilitas $(\mathrm{p})<0,05$, maka hal ini berarti bahwa kepuasan dan kepercayaan secara bersama-sama berpengaruh positif komitmen dan signifikan terhadap komitmen.

Dari hasil pengujian diperoleh nilai $\mathrm{F}$ hitung sebesar 22,000 dengan nilai probabilitas sebesar 0,000. Berdasarkan dengan ketentuan uji $\mathrm{F}$ dimana nilai probabilitas $(\mathrm{p})<0,05$, maka hal ini berarti bahwa kepuasan, kepercayaan dan komitmen secara bersama-sama berpengaruh positif loyalitas pelanggan dan signifikan terhadap loyalitas pelanggan, dengan demikian, hipotesis diterima.

\section{Uji sobel}

Pengaruh tidak langsung kepuasan dan kepercayaan terhadap loyalitas pelanggan melalui variabel komitmen sebagai variabel intervening

$$
\frac{a b}{\sqrt[9]{\left(b^{2} S E_{a}^{2}\right)+\left(a^{2} S E_{b}^{2}\right)}}
$$

a: direct effect kepuasan terhadap komitmen $=0,643$

b: direct effect komitmen terhadap loyalitas pelanggan $=0,110$

SEa: Standar Error dari a = 0,089

$\mathrm{SEb}$ : Standar Error dari $b=0,052$

$$
\begin{aligned}
& Z=\frac{0,643 \times 0.110}{\sqrt{0.110^{2} \times 0.089^{2}}+\left(0.643^{2} \times 0.052^{2}\right)} \\
& Z=\frac{0.07073}{\sqrt{0.0012138102}} \\
& Z=\frac{0.07073}{0.034839779} \\
& Z=2,0301506505
\end{aligned}
$$

Dari hasil perhitungan sobel test di atas mendapatkan nilai z sebesar 2,0301506505, karena nilai z yang diperoleh sebesar 2,0301506505>1.984 dengan tingkat signifikansi 5\% yang menunjukkan bahwa hipotesisi kepuasan berpengaruh positif terhadap loyalitas pelanggan melalui komitmen diterima. 
Pengaruh tidak langsung kepercayaan terhadap loyalitas pelanggan melalui variabel komitmen sebagai variabel intervening.

$$
\frac{a b}{\sqrt[3]{\left(b^{2} S E_{a}^{2}\right)+\left(a^{2} S E_{b}^{2}\right)}}
$$

a: direct effect kepercayaan terhadap komitmen $=0,373$

$\mathrm{b}$ : direct effect $\mathrm{komitmen}$ terhadap loyalitas pelanggan $=0,110$

SEa: Standar Error dari a $=0,079$

SEb: Standar Error dari $b=0,052$

$$
\begin{aligned}
& Z=\frac{0.373 \times 0.110}{\sqrt{\left(0.110^{2} \times 0.079^{2}\right)+\left(0.373^{2} \times 0.052^{2}\right)}} \\
& Z=\frac{0.04103}{\sqrt{ } 0.0004517209} \\
& Z=\frac{0.04103}{0.02125372667} \\
& Z=1.9304849723
\end{aligned}
$$

\section{KESIMPULAN DAN SARAN}

Berdasarkan pada hasil penelitian dan pembahasan yang telah diuraikan pada bab sebelumnya, maka pada penelitian ini dapat diambil kesimpulan bahwa:

- Kepuasan berpengaruh positif terhadap terhadap komitmen pengguna layanan jasa pengiriman JNE di Yogyakarta.

- Kepercayaan berpengaruh positif terhadap terhadap komitmen pengguna layanan jasa pengiriman JNE di Yogyakarta.

- Komitmen berpengaruh positif terhadap terhadap loyalitas pelanggan pengguna layanan jasa pengiriman JNE di Yogyakarta.

- Kepuasan berpengaruh positif terhadap terhadap loyalitas pelanggan pengguna layanan jasa pengiriman JNE di Yogyakarta.

- Kepercayaan berpengaruh positif terhadap terhadap loyalitas pelanggan pengguna layanan jasa pengiriman JNE di Yogyakarta.

- Kepuasan dan kepercayaan mempunyai pengaruh positif dan langsung terhadap komitmen pelanggan JNE cabang Yogyakarta

- Kepuasan dan kepercayaan berpengaruh positif terhadap loyalitas pelanggan secara langsung ataupun melalui komitmen layanan jasa pengiriman JNE di Yogyakarta.

- Kepuasan berpengaruh positif terhadap loyalitas pelanggan secara langsung ataupun melalui komitmen layanan jasa pengiriman JNE di Yogyakarta.

- Kepercayaan berpengaruh positif terhadap loyalitas pelanggan secara langsung namun tidak pengaruh melalui komitmen layanan jasa pengiriman JNE di Yogyakarta melalui uji sobel. 
Berdasarkan pada kesimpulan tersebut di atas, maka peneliti mengajukan saran sebagai berikut:

a) Bagi Perusahaan

- Diharapkan untuk meningkatkan kepuasan pelanggan supaya terjadi loyalitas pelanggan agar perusahaan memperhatikan pelayanan dalam hal kecepatan dan ketepatan dalam melakukan pengiriman paket sesuai dengan pilihan kecepatan pengiriman agar pelanggan merasa puas dan senang karena pelayanan yang didapatkan sesuai dengan yang diingin dan sesuai harapan. Hal itulah yang menimbulkan loyalitas pelanggan. Sehingga pelanggan akan melakukan pembelian kembali.

- Hal yang perlu mendapat perhatian agar pelanggan percaya sehingga mereka berkomitmen untuk terus menggunakan JNE adalah dengan lebih memperhatikan kualitas layanan yang diberikan kepada pelanggan seperti bagaimana cara pegawai melayani pelanggan karena dari hasil penelitian indikator pegawai tidak membiarkan pelanggan menunggu memiliki mean terendah dibanding indikator lain, dan juga pegawai JNE bisa meningkatkan berkomunikasi yang terbuka dan jujur dengan pelanggan.

- Untuk meningkatkan komitmen yang perlu dilakukan adalah dengan cara memberikan keyakinan pada konsumen bahwa JNE adalah yang terpenting dan dapat memberikan pelayanan yang terbaik kepada pelanggan.

- Dengan memperhatikan indikator-indikator yang menunjang terjadinya kepuasan, kepercayaan serta komitmen diharapkan JNE dapat meningkat Loyalitas pelanggan.

b) Bagi Penelitian Selanjutnya

- Dapat dijadikan sebagai bahan pemikiran, pertimbangan atau bahan referensi dengan variabel penelitian kepuasan, kepercayaan, komitmen dan loyalitas pelanggan lebih lanjut.

- Untuk peneliti selanjutnya dalam bidang yang sama diharapkan dapat mencari variabel-variabel yang lain selain kepuasan, kepercayaan, komitmen dan loyalitas pelanggan. Seperti variabel kualitas layanan.

\section{DAFTAR PUSTAKA}

Affandi, E. Y., \& Sulistyawati, E. (2015). Peran Kepercayaan Tamu Dalam Memediasi Pengaruh Kepuasan Konsumen Terhadap Loyalitas Pelanggan Hotel Taman Agung. EJurnal Manajemen Unud, 4(4), 1119-1133.

Dharmesta, B. S. (2014). Manajemen Pemasaran Edisi 2. Universitas Terbuka

Dharmesta, B. S. dan Irawan, (2012). Manajemen Pemasaran Modern. Liberty, Yogyakarta.

Gofur, A. (2019). Pengaruh kualitas pelayanan dan harga terhadap kepuasan pelanggan. Jurnal Riset Manajemen Dan Bisnis (JRMB) Fakultas Ekonomi UNIAT, 4(1), 37-44.

Handal, N. S. (2010). Analisis Pengaruh Experiential Marketing Terhadap Loyalitas. Jurnal Manajemen Universitas Diponegoro, 2(2), 15-20. 
Idris, I., Sari, P. D., Ali, Y., Aisyah, S., \& Hadi, A. S. (2019). The Effect of taxi bike Service Quality on Customer Satisfaction among Students. In ICASI 2019: Proceedings of The 2nd International Conference On Advance And Scientific Innovation, ICASI 2019, 18 July, Banda Aceh, Indonesia (p. 1). European Alliance for Innovation.

Kotler, P., \& Keller, K. L. (2016). A framework for marketing management. Boston, MA: Pearson.

Lupiyoadi, R. dan Hamdani, A. (2008). Manajemen Pemasaran Jasa, Jilid dua, Cetakan Keempat. Jakarta: Salemba Empat.

Muzammil, A., Yunus, M., \& Darsono, N. (2018). Pengaruh Kualitas Pelayanan Dan Citra Perusahaan Terhadap Loyalitas Pelanggan Indihome Pt. Telkom Indonesia Di Banda Aceh Dengan Kepuasan Dan Kepercayaan Pelanggan Sebagai Variabel Mediasi. Jurnal Manajemen Inovasi, 8(3), 104-133.

Rofiq, A., \& Mula, J. M. (2010). The effect of customers' trust on e-commerce: A survey of Indonesian customer B to C transactions. International Conference on Arts, Social Sciences \& Technology, Penang, Malaysia, 24-25.

Tjiptono (2006). Service Management Mewujudkan Layanan Prima. Andi, Yogyakarta. 